\title{
Measurement and Forecasting of Port Tide Hydrostatic Component in North Tyrrhenian Sea (Italy)
}

\author{
Osvaldo Faggioni ${ }^{1,2}$ \\ ${ }^{1}$ Istituto Nazionale di Geofisica e Vulcanologia, Via di Vigna Murata, Roma, Italy \\ ${ }^{2}$ Applied Computational Metrology Lab, INGV-Università di Genova, Via Carducci, La Spezia, Italy \\ Email: osvaldo.faggioni@ingv.it
}

How to cite this paper: Faggioni, O. (2020) Measurement and Forecasting of Port Tide Hydrostatic Component in North Tyrrhenian Sea (Italy). Open Journal of Marine Science, 10, 52-77.

https://doi.org/10.4236/ojms.2020.102005

Received: November 20, 2019

Accepted: April 19, 2020

Published: April 22, 2020

Copyright $\odot 2020$ by author(s) and Scientific Research Publishing Inc. This work is licensed under the Creative Commons Attribution International License (CC BY 4.0).

http://creativecommons.org/licenses/by/4.0/ (c) (i) Open Access

\begin{abstract}
Starting from the end of the 90s not perodic and unpredictable variations in the depth of harbor waters were observed. Long period (from 24 hours to a few days) and wide amplitude are their main features. Experience showed that this phenomenon is a risk for harbor navigation and mooring. It may be a serious obstacle to waterside port activities. The first observation of the data does not link the super-highs and the super-dry tides to the meteorological dynamic of sea-atmosphere interaction (i.e. Storm Effect). More, the attempt to compensate for these sea depth fluctuations by means of the well-known offshore hydrobarometric inverse parameter $(1[\mathrm{~cm}]$ sea level variation for -1 [hPa] atmospheric pressure variation) underestimates the amplitude of the phenomenon. In the first years of 2000, the Italian Ministry of Transport launched a national project for the definition of thee-amplitude and time of these tidal anomalous waves. The measure of harbors hydrobarometric inverse factors showed a much more intense value than the theoretical one (computed for the offshore). These amplification factors are characteristic of each harbor and can be double (in exceptional cases even more) than offshore. The delay between the arrival times of these tidal waves (induced phenomenon) respect to the time of arrival of the atmospheric pressure variation (inducing phenomenon) depends on 1) morphology of the port basin sea floor and 2) harbor and off-shre water dynamics relationship (first approximation). For these reasons the hydro barometric inverse parameter is not effectiveness computable but it can be determined statistically.
\end{abstract}

\section{Keywords}

Coastal and Port Tides, Hydrostatic Component, Gravimetric Measurements, Safety of Port Navigation and Docking 


\section{Rationale}

\subsection{The Goal of the Research}

From 2000-2005 many Italian Port Authorities have detected anomalous fluctuations in the depth of port waters. These events created an obstacle to port navigation and, more generally, to the merchant activities of the port. A qualitative and preliminary study showed these phenomena were connected to the local variation of atmospheric pressure. The phenomena were not predictable in amplitude, time of arrival, and duration. The law linking the inducing phenomenon (variation of atmospheric pressure) to the induced phenomenon (hydrostatic balancing tide of the port basin) was not available. The purpose of the present research is the definition of the hydrostatic compensation law in port basins and therefore the ability to predict the hydrostatic port-coastal compensation tide. The forecast of these events increases the safety of coastal and port navigation, of the ports waterside activities and allows optimizing the use of piers and docks.

\subsection{Short Description of the Phenomenon}

The port waters depth fluctuation due to the tide is the natural phenomenon having the greatest influence on port-coastal navigation and it can interfere with ships admittance capability to the docks. These limitations to port activities are more evident when the depth of the port basin is low. A port with shallow access routes is forced to work with ships with reduced displacement or with ships not fully loaded. The productivity limits of the port due to this phenomenon are evident and very studied. Under these conditions the tide action is the object of particular attention by the port management. The scientific approach to the problem of the variation of harbors waters depth is based on two aspects modifying the bathymetry of the ports: the control of the sediments deposition on the seabed and the forecast of the tide. The accumulation of sediment on the seabed can be considered a medium-long term phenomenon (apart from rare cases) and it is controlled with direct measurements of depth, generally of an acoustic type. Its contrast is based on the dredging operations of the seabed that are part of the normal life of many ports. Instead the action of the tide produces variations in sea water highness with a shorter period. The capability to forecast the tides is fundamental for optimizing the port navigation security and docks activity. The tide is constituted only in part by a periodic component of astronomical origin well modeled and therefore predictable (astro-tide). This component $(\alpha) 1)$ is produced to a very large extent by the gravitational effects of the dynamic Newtonian system Earth-Sun-Moon (Figure 1) and is formally coded. Table 1 shows the main periods of $\alpha$ for the Mediterranean Sea.

The values of Table 1 are calculated according on the earth's surface gravitational potential generated by the Planet Earth and the surrounding sky bodies (Sun and Moon). However, the empirical reality is more complex than described by the geopotential model of astronomical Newtonian interaction and includes important aperiodic components of meteorological origin defined by (1) (Figure 
1) $[1][2]$

$$
F_{t}=\alpha+\beta+\gamma \cong F_{g} 10^{-7}
$$

$\beta$ and $\gamma$ (Figure 1) are coming from the Newtonian interaction of the terrestrial liquid district (sea) with the gaseous one (atmosphere). The first meteorological component (meteo-kinetic tide $\beta$ ) is generated by frictional energy exchanges between the sea and the atmosphere. [3]. With good approximation we can define it as the transfer of kinetic energy from the atmosphere to the sea. The second one meteorological tide component is the hydrostatic ( $\gamma$ ) (also called Newtonian tidal wave or slow-dynamic tide). It is the geodetic adaptation of the sea surface to varying atmosphere weight [4]. $\beta$ and $\gamma$ are therefore variations in the level of the sea surface due to atmospheric forcing. We then define, in a first approximation, the tide be composed of three main components: astronomical tide (component $\alpha$ ), meteo-kinetic tide (component $\beta$ ), tide-hydrostatic (or Newtonian) (component $\gamma$ ) 1). The $\beta$ component depends on clearly visible meteorological phenomena and is therefore generally well known. To a large extent this component is connected to the water accumulation or port basin emptying due to wind action. It essentially depends on the direction and strength of the wind and is part of the empirical classification of "storm effects". $\beta$ is aperiodic but is controllable by the easy observation of the atmospheric dynamics that induces it Different is the condition of $\gamma$ coming from the local variation of atmospheric pressure and therefore less observable by a non-instrumental way [5].

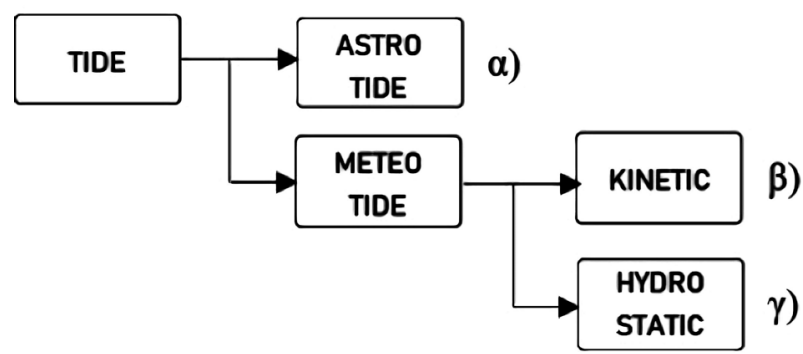

Figure 1. Tide's components: $\alpha=$ astronomical origin; $\beta$ and $\gamma=$ meteorological origin ( $\beta$ $=$ atmospheric kinetic origin, $\gamma=$ hydrostatic origin).

Table 1. Astronomical component amplitude of the Mediterranean Sea main tide periods. column 1, Harm = harmonic, $\operatorname{clm} 2, T=$ period, $\operatorname{clm}, 3 \mathrm{~V}=$ speed.

\begin{tabular}{ccc}
\hline Harm. & $T[\approx \mathrm{h}]$ & $\boldsymbol{v}\left[{ }^{\circ} / \mathrm{h}\right]$ \\
\hline M2 & 12 & 28.9841 \\
S2 & 12 & 30 \\
N2 & 12 & 28.43973 \\
K2 & 12 & 30.08214 \\
K1 & 24 & 15.04107 \\
O1 & 24 & 13.94306 \\
P1 & 24 & 14.95893 \\
S1 & 24 & 15 \\
M4 & 6 & 57.97 \\
MS4 & 6 & 58.98 \\
\hline
\end{tabular}


Figure 2 shows the phenomenon of the hydrostatic tide. The local column of the fluid terrestrial district (atmospheric and sea) in standard conditions is in geodetic equilibrium.

If for meteorological reasons the weight of the gaseous district (atmosphere) varies (increase or decrease in density), the local column loses its condition of geodetic equilibrium (Figure 2) [6]. The liquid district cannot compensate for this isostatic equilibrium by varying its density and therefore the compensation occurs by expulsion (or recall) of water mass in the local column volume. The flexure of the geodetic surface of the liquid is therefore inverse with respect to the variation of atmospheric pressure (increase in the density of the atmosphere decrease in the quotee of the sea surface and vice versa). This phenomenon is well known. In offshore environment, it is worth about $1[\mathrm{~cm}]$ of sea level e increasing for a loses - $1[\mathrm{hPa}]$ of atmospheric pressure (hydro-barometric inverse factor $J_{p}$ ) [7]. $J_{p}=1 / 1$ (inverse) is the value reported by the standard nautical technical documents for maritime navigation. This value does not take into account $J_{p}$ small variations due to sea water density variation but it is nevertheless an excellent approximation for offshore navigation. But experience has shown that in port basins the amplitude value (abs) of $J_{p}=1 / 1[\mathrm{~cm} / \mathrm{hPa}]$ may not be sufficiently accurate to guarantee the safety of port activities [8]. The systematic observation of some Italian ports showed values of $J_{p}$ of amplitude 1.5/1 or 2/1 $[\mathrm{cm} / \mathrm{hPa}]$ and in some cases even higher. As far as port navigation is concerned and, above all, docks operations the sea level compensation for a $J_{p}=1 / 1$ $[\mathrm{cm} / \mathrm{hPa}]$ can lead to unacceptable forecast errors.

\section{Harbour Hydrostatic-Tide Waves: A Preliminary Quantitative View}

Before looking at the $J_{p}$ factor quantization method (abs value) it is good to clarify

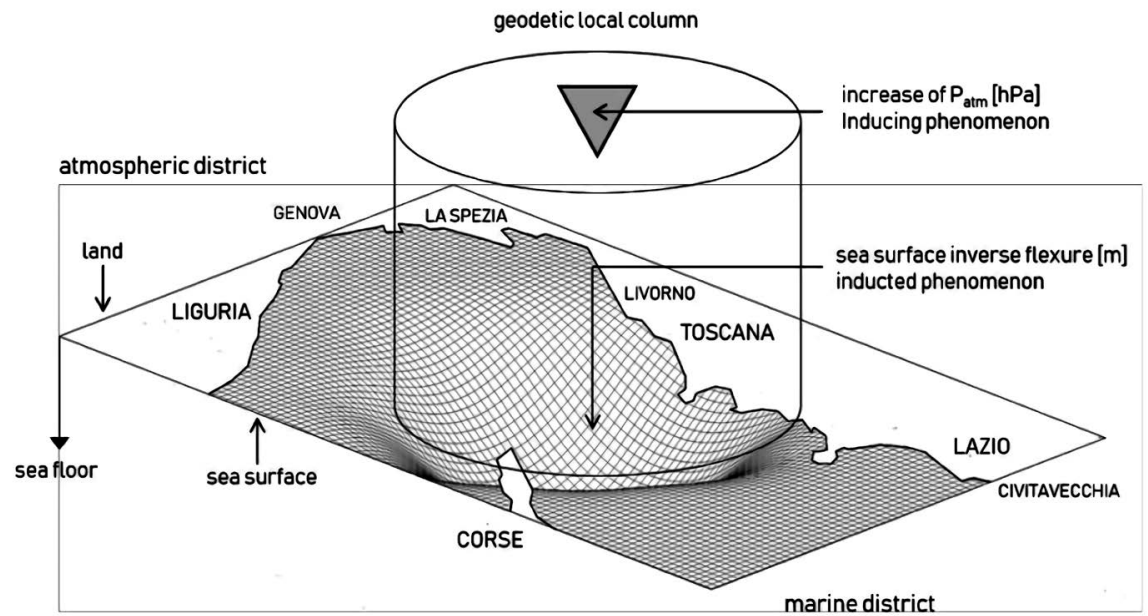

Figure 2. The phenomenon of hydrostatic compensation of the sea surface to the variation of atmospheric pressure in The Tyrrhenian Sea. Gray triangle: symbol of increased atmosphere weight. Concave curvature of the sea surface: hydrostatic compensation reaction of the marine district to the change in the weight of the atmosphere. Pictorial image. 
with a preliminary example the real value of the hydrostatic compensation tide (induced phenomenon) with respect to thveatmosphere weight local variation (inducing phenomenon). As is known in offshore the mass of water involved in the phenomenon of hydrostatic compensation is free to move in any direction of the three-dimensional space Instead along the coasts the horizontal component of the compensation motion is inhibited by the presence of the coast. The compensation defect due to the inhibition of the horizontal compensation movements is discharged on the vertical ones accentuating them (semi-binding basin effect $=$ basin closed in one direction only). To quantify preliminarily this effect, we observe the value of $J_{p}$ in the event recorded in the port of Civitavecchia from 00.00 january 012010 to 24.00 january 072010 (Figure 3). In this time a high pressure event of the period $T=13 \rightarrow 121[\mathrm{~h}]=108[\mathrm{~h}]$ develops with a maximum pressure variation $\triangle \mathrm{PMAX}=1016-995=21[\mathrm{hPa}]$. In the same period the water compensation motion in the port of Civitavecchia generates a vertical difference in height $\Delta H=-1 \rightarrow-39=-38[\mathrm{~cm}]$. The hydrobrometric factor (abs) for this event for this harbour is therefore $J_{p}=38 / 21=1.8[\mathrm{~cm} / \mathrm{hPa}]$. Applying the compensation from standard inverse hydro-barometric factor $(1 / 1)$ an error is made $\varepsilon=0.8[\mathrm{~cm} / \mathrm{hPa}] \approx 17[\mathrm{~cm}]$. This $\varepsilon$ 's amplitude is such as to create

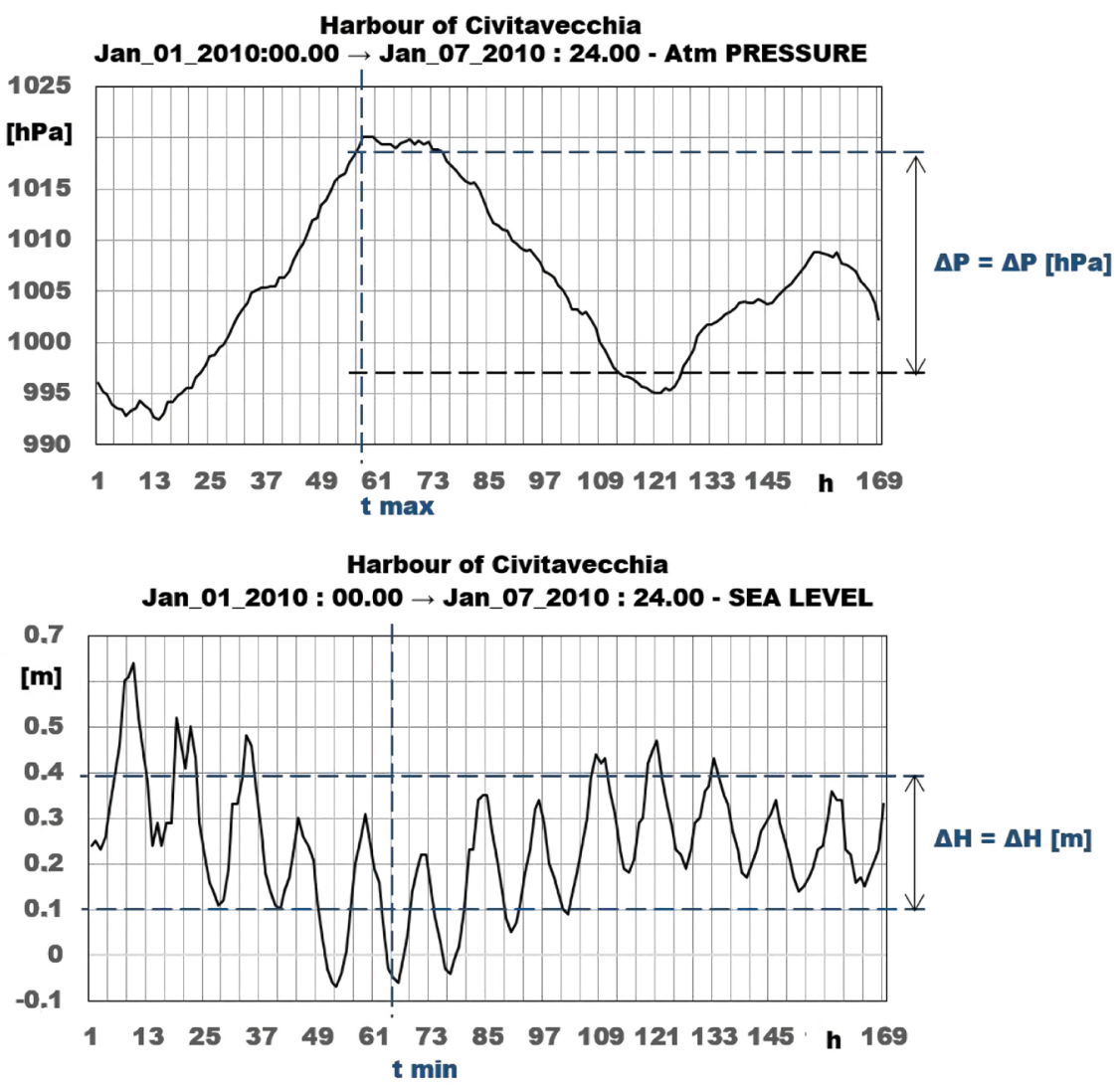

Figure 3. Port of Civitavecchia. Data set: 00.00 january 012010 at 00.00 january 012010 (Figure 3). Duration of the event: $T=13[\mathrm{~h}] \rightarrow 121[\mathrm{~h}]=108[\mathrm{~h}]$. Pressure variation $\triangle \mathrm{PMAX}=1016-995=21[\mathrm{hPa}]$. Sea level change due to hydrostatic compensation $\Delta H$ $=-39-(-1)=-38[\mathrm{~cm}]$. 
possible interferences both the port navigation (ship's draft-depth of the sea bottom) and the docks loading-unloading operations. In practice, in the present case, assuming a port water depth of $850[\mathrm{~cm}]$, the standard hydro-barometric compensation forecast e a water residue of $829[\mathrm{~cm}]$ while the real residue is $812[\mathrm{~cm}]$ (real event). The interference of this $\varepsilon$ is a known and documented risk from many years of port activities observation. These types of tide, having anomalous amplitudes with respect to astronomical one, are called super-high or super-dry (or super low). The risks due to these events are classified into three groups: the ordinary obstacles to the port navigation and to the loading-unloading works, the straordinary accidents (i.e. stranding), the warning in the design of the harbour coast line and sea bottom infrastructures For example, experience has shown that if the super-dry phenomenon is not expected, the heaviest maritime traffic is exposed to the risk of keel-sea bottom contact even in the most safe access routes to the docks. Often these accidents are interpreted with the presence of new accumulations of sediments on the seabed (confusing the temporary water decreasing with an apparent phenomenon of rising seabed). On the contrary, the super-highs can generate problems in the mooring lines due to the increase in the level of buoyancy of the ship and consequent over-tension of the mooring cables themselves. These effects can be amplified in extraordinary activity, for examples, for ships refloating actions or wrecks removal actions. Another aspect of particular attention is the interference of the $\gamma$-type tide component with the design of maritime coastal structures.

Low pressure $\gamma$-type tides persist for long periods (from a few hours to a few days). If, for example, during these meteorological-marine conditions the wave motion develops, the peaks of the waves will develop on a sea level higher than the standard one and therefore higher structures $s$ will be needed to contain them. With the same degree of sea state to be contained, it will be necessary to have to a greater raising of the containment structure. On the contrary, this phenomenon requires deeper dredging to ensure safe ships transit even in the worst conditions of $\gamma$.

\section{Steps of the Forecasting Method: A Preliminary Overview}

The problem of the measurement and prediction of hydrostatic balancing port tides was addressed from a statistical point of view. The measurement-calculation flow is based on the following steps:

Forecast computation of the amplitude:

- Measures and normalized comparison of the amplitude of the change in atmospheric pressure and the amplitude of the compensating tidal wave.

- Statistical calculation of the numerical correlation factor between signal pressure amplitude and sea level signal amplitude (dimensional factor).

- Application of the numerical compensation factor to the meteorological forecast of the amplitude of pressure variation to obtain the prediction of the sea level variation. 
The time arrive computation and the forecast o the tide delay with respect to the variation in atmospheric pressure is obtained by replacing the amplitude of the signals with their arrival time.

The prediction can also be based on the measurement of the gravity acceleration variation (by means of the gravimeter). The flow of calculation remains the same. In the amplitude forecast, the gravity acceleration value replaces the atmospheric pressure value. The forecast procedure based on the gravity measure has a higher order of precision but the gravimetric measure systems is significantly more expensive.

\section{Measure and Computation of the Hydrostatic Balancing Parameters}

At today the definition of the hydrostatic relationship between the variation of the atmosfere weight and the sea level in natural or artificial coastal basins cannot be effectively modeled due to the high number of physical-geographical factors involved in the phenomenon. This defect exists both the modeling of the amplitudes of $\gamma$ and for the fluid response times of the basin (time of arrival of the force inducing the geodetic imbalance, delay necessary for marine dynamics for rebalancing). The non-modelability condition is due to the morphological characteristics of each port and to the dynamic relationships between port waters and the marine circulation of its offshore. We propose new statistical parameters $\left(J_{p}, J_{g}, K\right)$ that allow to describe quantitatively the phenomenon both in amplitude and in time of arrival. The parameters $J_{p}, J_{g}, K$ are called "Harbor Newtonian Parameters" (Figure 4).

The $J$ factors (also called transfer Newtonian factors) formalize the amplitude relationship between the induced phenomenon and of the inducing one [9]. They are, of course, dimensional factors The factors $J_{p}$ (factor of $1^{\text {st }}$ order) and $J_{g}$ (factor of $2^{\text {nd }}$ order) control the amplitude ratios between the variation of the weight of the atmosphere and the variation of the sea level. The first order factor

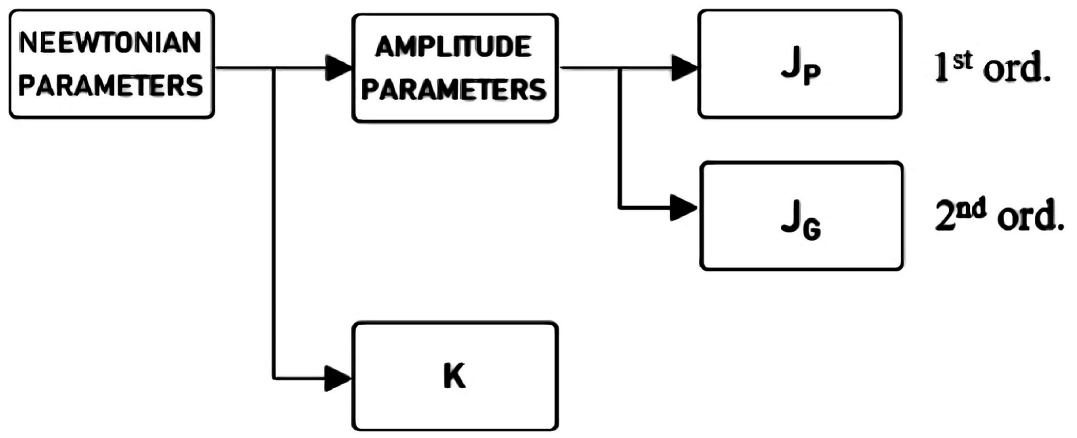

Figure 4. Morphology of the relationship atmospheric pressure variation (inducing phenomenon) sea level variation (induced phenomenon). $J_{p}=$ quantitative relationship between atmospheric pressure variation and sea level variation (1st order); $J_{g}=$ quantitative ratio of variation in local gravity and variation in sea level ( 2 nd order). $K$ delay between the arrival of the inductor phenomenon and the arrival of hydrostatic compensation (hydro-barometric tide). 
$J_{p}$ normalizes the variation of sea level measured by the mareograph to the variation of atmospheric pressure measured by means of the barometer according to the Equation (2)

$$
J_{p}=\frac{\Delta h[\mathrm{~m}]}{\Delta p[\mathrm{hPa}]}
$$

The second order factor $J_{g}$ normalizes the variation of sea level measured by the mareograph to the variation of acceleration of gravity measured by means of a gravimeter according to the Equation (3)

$$
J_{g}=\frac{\Delta h[\mathrm{~m}]}{\Delta g[\mu \mathrm{gal}]}
$$

The translation of the inducing quantities expressed in $[\mathrm{hPa}]\left(1^{\text {st }}\right.$ order$)$ or in [ $\mu \mathrm{gal}]\left(2^{\text {nd }}\right.$ order$)$ in the corresponding induced quantity expressed in $[\mathrm{m}]$ is shown in the dimensional analysis (4).

$$
\Delta h[\mathrm{~m}]\left\{\begin{array}{l}
\Delta p[\mathrm{hPa}] \times J_{p} \frac{\Delta h[\mathrm{~m}]}{\Delta p[\mathrm{hPa}]} \\
\Delta g[\mu \mathrm{gal}] \times J_{g} \frac{\Delta h[\mathrm{~m}]}{\Delta g[\mu \mathrm{gal}]}
\end{array}\right.
$$

The first-order factor $J_{p}$ has a negative value (inverse) while the second-order factor $J_{g}$ is direct.

\section{1. $J_{p}$ the Ist 0 rder $J$ Factor-Barometer}

$J_{p}$ is the most used parameter, at today when we speak generically of $J$ factor we mean the 1st order hydrobarometric inverse factor based on the merge of the signals detected by the barometer with those detected by the mareograph [10]. No instrumental equipment other than of a standard mareograph station is required (Figure 5). For this reason this technique is directly applicable in any harbour and it is currently the most used.

The prediction of changes in the depth of the port basin is therefore obtained by multiplying the hydro barometric inverse factor by the measured or expected pressure (meteorological forecast). To date, on an experimental basis it is possible to produce operative forecasts of hydrostatic variations at $6,12,18,24,30$ hours for the ports of which the $J_{p}$ factor is known (Table 2). The values of Table 2 were calculated considering super-high and super-dry events developed with wind speed $v<3$ [knots] (Light air - 1 Beaufort Scale) to avoid possible contributions by $\beta$ component (Figure 1). (Note: this condition is applied to every event put into statistics in this research).

Table 2 shows two evidences: 1 ) the ports of the Tyrrhenian basin (Distreict 1 - N Thyrrenian, Figure 6(a)) have similar behaviors with hydrostatic responses of average amplitude of about $=2[\mathrm{~cm}]$ for $1[\mathrm{hPa}]$, for exception of the port of Civitavecchia showing a less intense average response $(1.7 \mathrm{~cm}$ per $\mathrm{hPa}) ; 2)$ the channel port of Ravenna, of different sea basin (District 6 - Adriatic, Figure $6(\mathrm{a}))$, shows a decidedly more intense average response $(2.8 \mathrm{~cm}$ per hPa). 


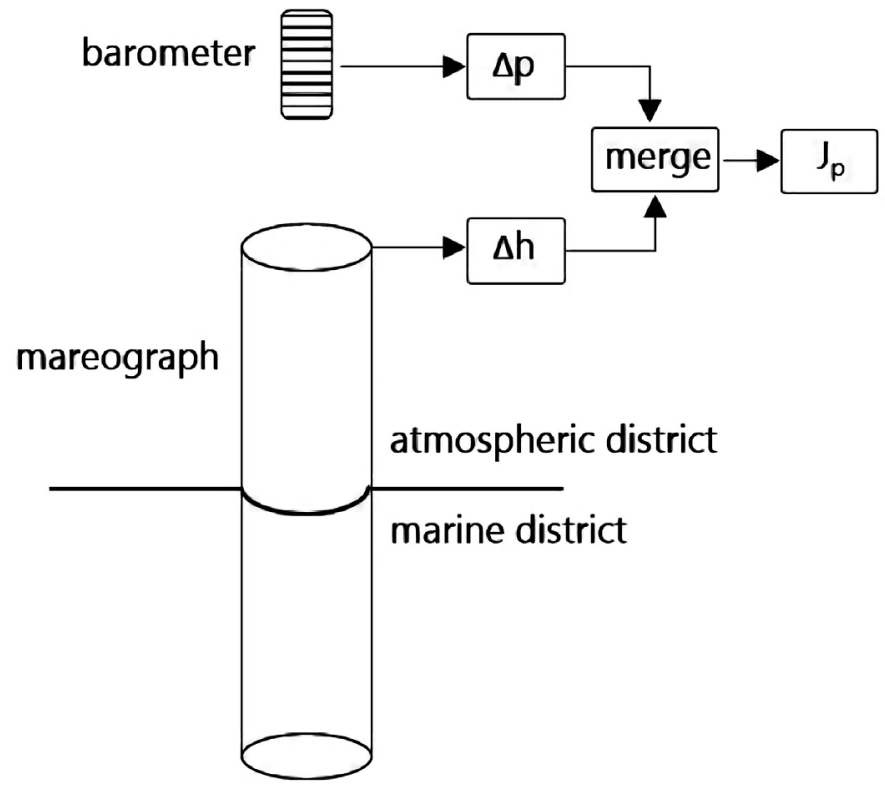

Figure 5. Basic scheme of mareographyc station ( $1^{\text {st }}$ order): the barometer provides the pressure variation measure, the mareograph the sea level variation. The comparison between the two signals indicates the multiplier factor (dimensional) $J_{p}$ for each measured event. The general port $J_{P}$ (also known as the $J$ standard) is calculated on a statistical basis (at least 10 events).

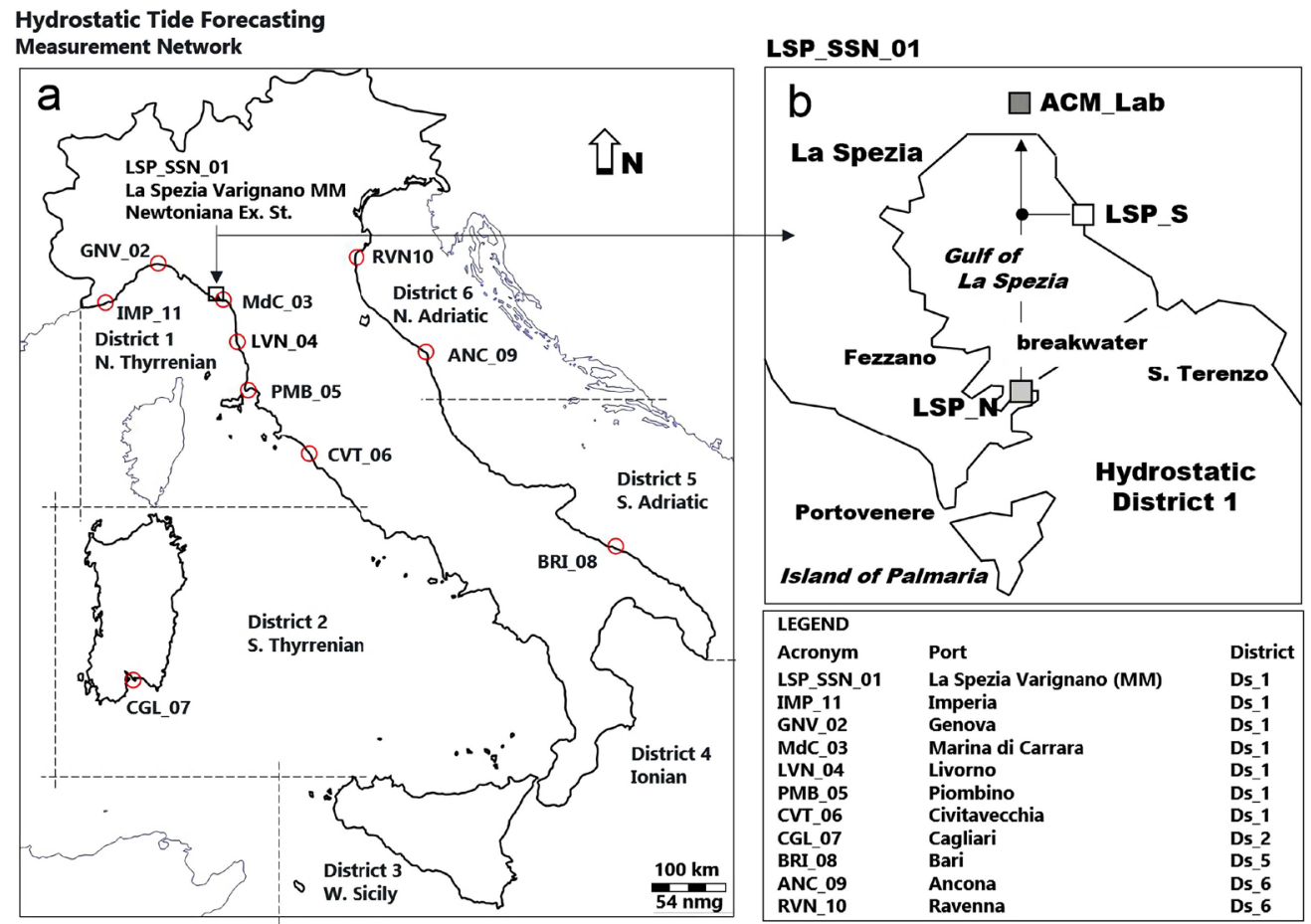

Figure 6. (a) Observation network of the tidal phenomenon of super-high and super-dry. Red circles: standard meteorological stations (barometer and mareograph); black square: Newtonian station (barometer, mareograp, gravimeter). (b) detail of the location of the Newtonian station (Gulf of La Spezia): standard component LSP_S (Porto Lotti SpA), Newtonian component (gravimeter) LSP_N (Varignano). Districts 1 ... 6: italian maritime areas study sectors. Legend. Column 1 Acronym, clm 2 Name of the harbour, clm 3 Hydrostatic maritime District. 
Table 2. Available $J_{p}$ values (at 2018) of the italian meteomareographic network (Figure 6). column 1, 1 = Harbour, clm 2, Adm = Public Administration of reference for the experiment $(\mathrm{AP}=$ Port Autorities, $\mathrm{MM}=$ Italian Navy), clm 3, $D=$ hydrostaic maritime district, $\operatorname{clm} 4, T=$ time of observation, $\operatorname{clm} 5, N=$ number of observed phenomena, clm 6. $J_{p}=$ hydrobarometric factor value, $\operatorname{clm} 7, \sigma=$ dispersion.

\begin{tabular}{ccccccc}
\hline Harbour & Adm & $\boldsymbol{D}$ & $\boldsymbol{T}$ [year] & $\boldsymbol{N}$ & $\boldsymbol{J}_{\boldsymbol{\mu}}[\mathrm{cm} / \mathrm{hPa}]$ & $\boldsymbol{\sigma}$ \\
\hline GENOVA & AP & 1 & 2 & 14 & 1.9 & 0.2 \\
LA SPEZIA & MM & 1 & 6 & 44 & 2.0 & 0.2 \\
MARINA di CARRARA & AP & 1 & 1 & 9 & 2.1 & 0.3 \\
LIVORNO & AP & 1 & 3 & 23 & 2.0 & 0.2 \\
PIOMBINO & AP & 1 & - & COMPUTED & 1.8 & - \\
CIVITAVECCHIA & AP & 1 & 2 & 14 & 1.7 & 0.3 \\
RAVENNA & AP & 2 & 1 & 10 & 2.8 & 0.8 \\
\hline
\end{tabular}

This singularity can be connected both to hydrostatic characteristics of the District 6 with respect to the Hydrostatic District 1 and to the specific morphology of the port of Ravenna (port channel).

\section{2. $J_{g}$ the II ${ }^{\text {nd }}$ Order $J$ Factor-Gravimeter}

As described above the $1^{\text {st }}$ order factor $J_{p}$ bases its performance on the measurement of atmospheric pressure variation. But this parameter does not act directly on the hydrostatics of the basin which, in the final analysis, is governed by the variation in the acceleration of gravity, induced by the weight variation of the gaseous district in the local column (Figure 2). From a strictly metrological point of view we can say that the barometric measure generating $J_{p}$ is an indirect one. In order to obtain higher order predictive accuracy (2nd order), especially in the computation of the phase shift between the inducing signals and the induced signals (delay of the hydrostatic tidal flow with respect to the weight change of the atmosphere) we propose the measurement of the local gravity variation $\Delta g$. The measurement is carried out by means of a Lacoste PET micro-g gravimeter (Portable Earth Tide gravimeter) (Figure 6(b), Figure 7) in a so-called Newtonian tide station (Figure 7). Particular attention must be taken in the positioning of this instrument which must operate in the atmospheric district and not too much sea surface.

This is because the surface of the sea, in a first approximation, can be considered the equipotential balance surface between atmosphere and sea and therefore the fluctuation of its geometric position is the sensitive element of the measure system. A too high position of the gravimeter $(>50[\mathrm{~m}])$ can produce the signal smoothing effect due to the distance from the phenomenon indicator compared to the measuring device. This measurement condition would increase the smoothing effect in a fatal way because the material interposed between the sensor and the sea surface is denser (water instead of air). In the Gulf of La Spezia a Newtonian meteomaregrafica station was built (Figure 6(a), Figure 6(b)) for the first direct hydrostatic tide measurement experiment (comparison beetwen sea level variation and local gravity acceleratison variation). The 


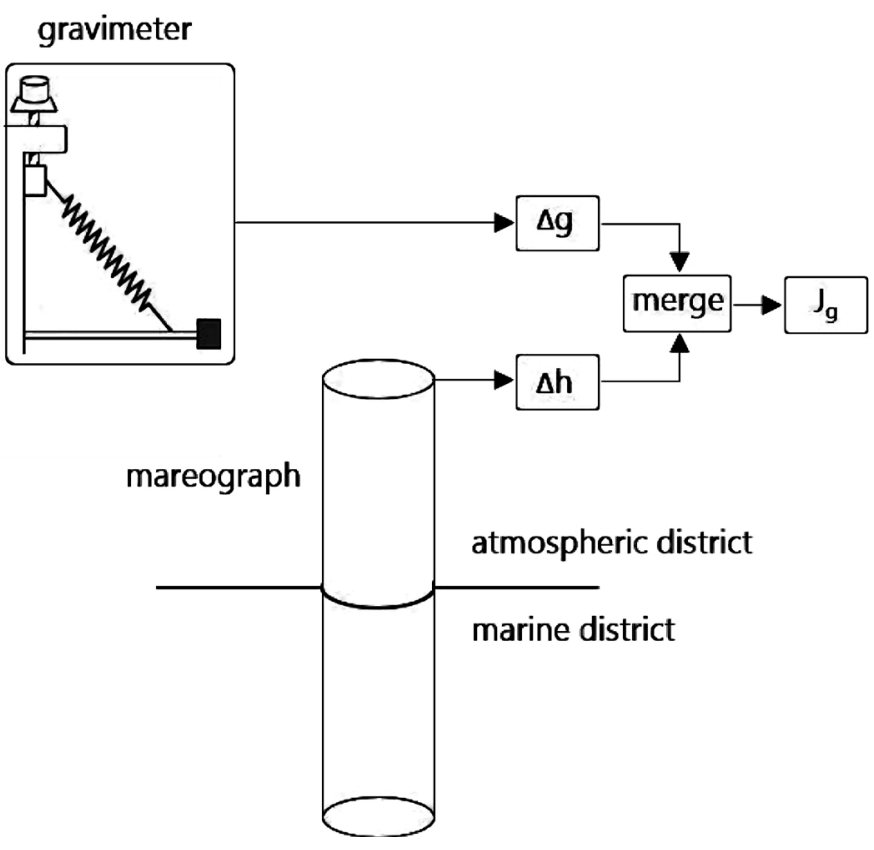

Figure 7. Basic scheme of newtonian mareographyc station ( $2^{\text {ud }}$ order): the gravimeter provides the local gravity variation measure, the mareograph the sea level variation. The comparison between the two signals indicates the multiplier factor (dimensional) $J_{g}$ for each measured event. The general port $J_{g}$ (also known as the $J$ standard) is calculated on a statistical basis (at least 10 events).

station, LSP_SSN_01 (La Spezia_Stazione Sperimentale Newtoniana_01) was built with the logistical-technological support of Italian Navy, the funding of EU-PRAI-FESR-Regione Liguria (NMS Technoproject) and the technical collaboration of ISPRA-Servizio Mareografico. The standard instrumental component (mareograph), owned by ISPRA, is located at a pier of the "Porto Lotti" Company of La Spezia, the Newtonian component (gravimeter) was located at Italian Navy Naval Base $(2007 \rightarrow 2012$ CSSN e $=1.68$ [m], La Spezia; $2013 \rightarrow$ 2016 COMSUBIN, $e=8.16[\mathrm{~m}]$, Dogana Settecentesca of Varignano) Figure $6(\mathrm{~b}))$. In the present example we show the results obtained in the study of the event of Figure 8 observed from the Newtonian meteorological station of La Spezia (code LSP_SSN_01; Figure 6(b)); period of observation 01_01_2010:00.00 $\rightarrow$ 01_07_2010:24:00 (sampling rate 60 [min], number of recorded samples = 168 , graphyc computation oversampling rate $=336$ [min], graphyc computation data set $=336[\mathrm{~s} \rightarrow$ samples. The results of the experiment are confirmed and officially acquired as $J_{g}$. for the gulf of La Spezia.

\section{The $J_{p, g}$ Factors Computation}

The results of the qualitative analysis of sea level changes in the port basins of Figure 6 provided the basis for starting the quantitative study of the problem. [11]. In particular, the $\gamma$ hydrostatic tide signals show much lower frequency (and amplitude of the same order or higher) with respect to $\alpha$ astro-tide signals. They therefore has high spectral visibility and high informative capacity and 


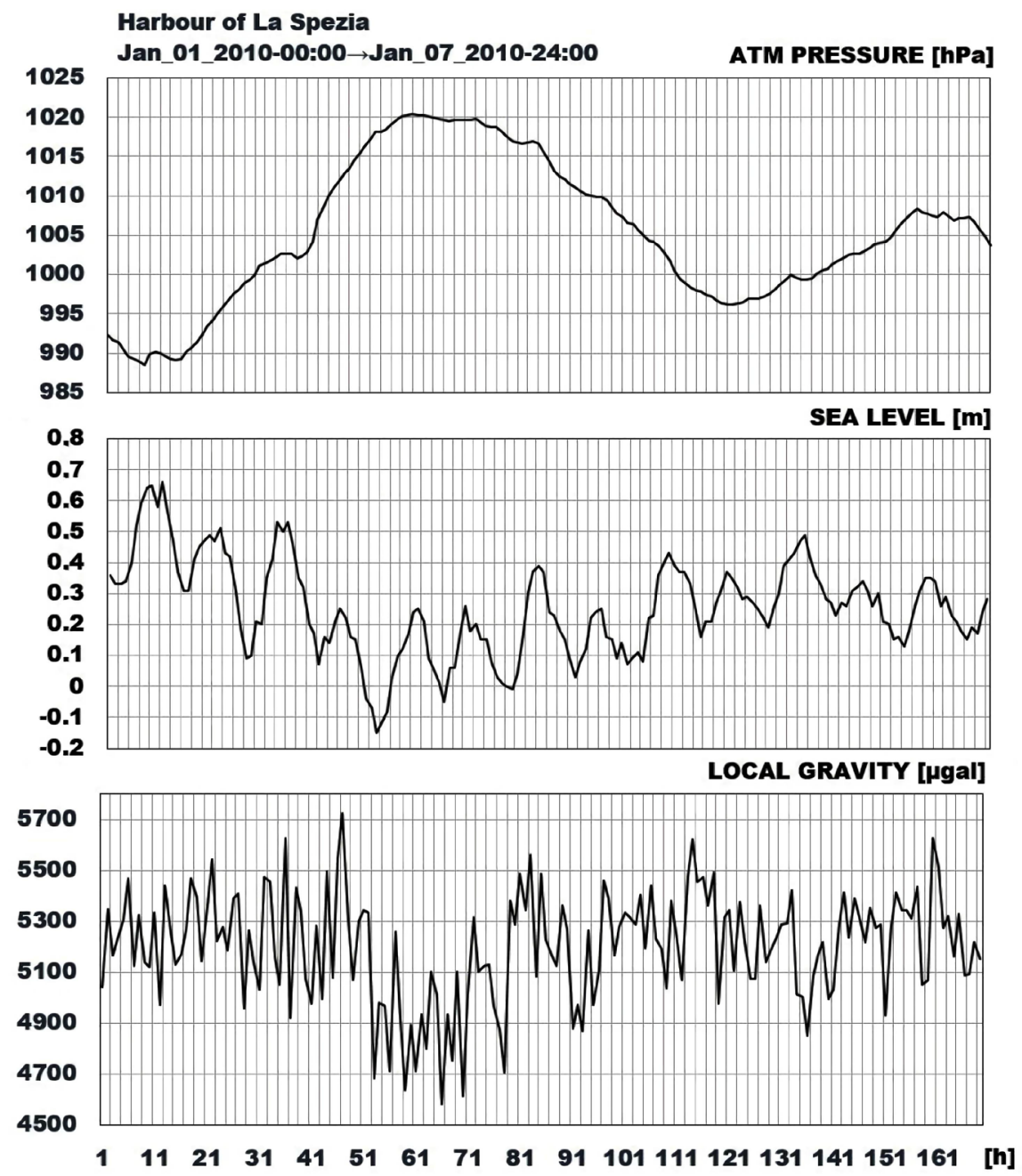

Figure 8. Example of registration of the Newtonian meteo-mareographyc station of La Spezia (code LSP_SSN_01); $X: 01 \_01 \_2010-00: 00 \rightarrow 01 \_07 \_2010-24: 00$ (Figure 7); $Y$ : first graph $=$ pressure variation $[\mathrm{hP}]$, second graph $=$ sea level variation $[\mathrm{m}]$, third graph $=$ local gravity variation $[\mu \mathrm{gal}]$; sampling rate $1[\mathrm{~h}]$.

they can be calculated effectively with Fourier analysis. [12]. In the case in question (Figure 9(a), Figure 9(b)) to compute the $J$ parameters the signals jan_02_2010: $00.00 \rightarrow$ jan_03_2010: 24.00 are considered (atmospheric pressure, gravity and sea level variations). The data was subjected to preliminary HP treatment in the wavelenght domain (correspondng to an LP filter in the frequency domain), they are a subset of the records of Figure 8 (period jan_01_2010: $00.00 \rightarrow$ jan_07_2010: 24.00. [s]). The measured series were oversampled with sampling step $s=1$ [min] (number of samples 10,080) to have greater stability in the calculation of the wavelengt HP filter (HP in wavelenght domain $=$ LP in frequency domain). The filter applied excludes the signals with wavelength $\lambda<18[\mathrm{~h}]$ The $J_{P}, J_{g}, K$ computation algorithm, $K$ is automatized by means the Fourier numerical operators (5), (6), (7):

$$
\Delta p=\sqrt{a_{p M}^{2}+b_{p M}^{2}}-\sqrt{a_{p m}^{2}+b_{p m}^{2}}
$$




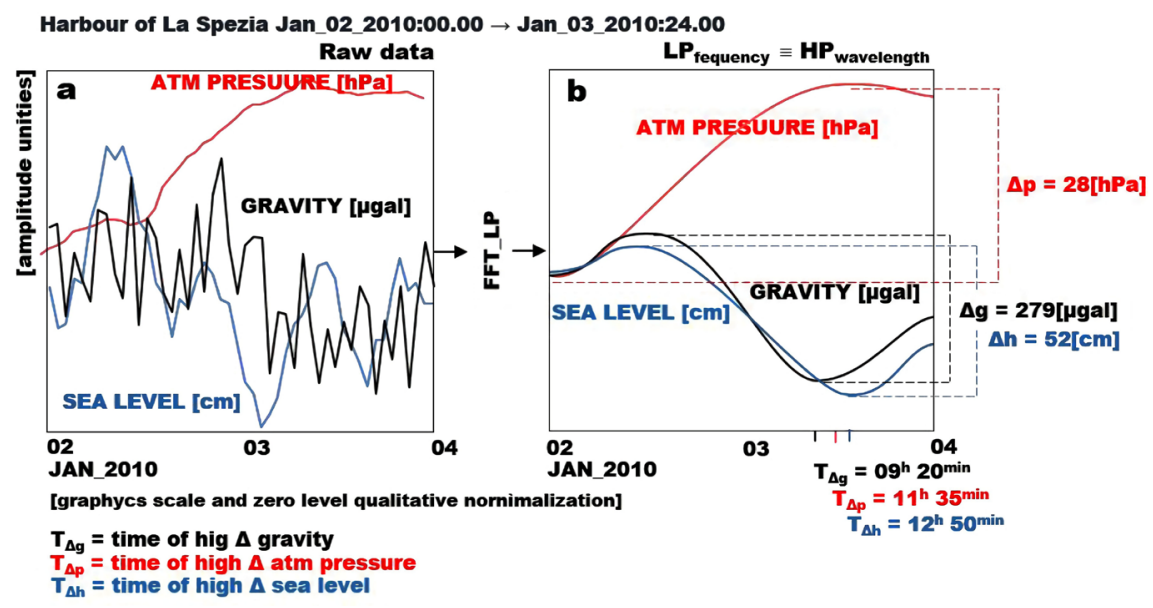

Figure 9. (a) Harbor of La Spezia, observation period jan_02_2010: 00. $==\rightarrow$ jan_04_2010: 00.00 (subset of Figure 8). $X=$ time (sampling rate of measure $=1[\mathrm{~h}]$ ); Y red $($ atmospheric pressure $)=[\mathrm{hPa}], Y$ blue $($ sea level $)=[\mathrm{m}], Y$ black $($ gravity $)=[\mu$ gal $]$, (graphic scales and zero level are normalized). Raw data. (b) signals filtered (HP $\lambda \geq 18$ [h]). Quantitative parameters: amplitude maxima $\Delta p=28$ [hP] (red), $\Delta g=279$ [ $\mu$ gal] (black), $\Delta h=0.52[\mathrm{~m}]$ (blue), delay of the sea level compensation respect to the measures (newtonian and standard) of the arrive of inducting phenomenonm aximum amplitude: $T \Delta g=$ jan_03_2010: 09.20 (black), $T \Delta p=$ jan_03_2010: 11.35 (red), $T \Delta I=$ jan_03_2010: 12.50 .

$$
\begin{aligned}
& \Delta g=\sqrt{a_{g M}^{2}+b_{g M}^{2}}-\sqrt{a_{g m}^{2}+b_{g m}^{2}} \\
& \Delta h=\sqrt{a_{h M}^{2}+b_{h M}^{2}}-\sqrt{a_{h m}^{2}+b_{h m}^{2}}
\end{aligned}
$$

where, according to the Fourier harmonic serie (8)

$$
f(t)=\frac{1}{2} a_{0}+\sum_{n=1}^{\infty}\left(a_{n} \cos \omega_{n} t+b_{n} \sin \omega_{n} t\right)
$$

$a_{0}$ is the carrier component of the signal and $a, b$ are the Fourier harmonic coefficients (10), (11):

$$
\begin{gathered}
a_{0}=\frac{2}{T} \int_{-T / 2}^{T / 2} f(t) \mathrm{d} t \\
a_{n}=\frac{2}{T} \int_{-T / 2}^{T / 2} f(t) \cos \omega_{n} t \mathrm{~d} t, n=0,1,2, \cdots \\
b_{n}=\frac{2}{T} \int_{-T / 2}^{T / 2} f(t) \sin \omega_{n} t \mathrm{~d} t, n=1,2, \cdots
\end{gathered}
$$

and

$\Delta p=$ atmospheric pressure variation.

$\Delta g=$ local gravity variation.

$\Delta h=$ sea bathymetry variation.

$p=$ atmospheric pressure.

$g=$ gravity.

$h=$ bathymetry.

$M, m=$ Maximum and minimum of the function. 
$T=$ period.

$t=$ time.

The results of the elaboration of the super-dry phenomenon of Figure 9(a) \& Figure 9(b) define the hydrostatic compensation parameters of the La Spezia Gulf:

$1^{\text {st }}$ order

$$
\left|J_{p}\right| \frac{\Delta h[\mathrm{~cm}]}{\Delta p[\mathrm{hPa}]}=\frac{49-(-3)}{1020-992}[\mathrm{~cm} / \mathrm{hPa}]=\frac{52}{28}[\mathrm{~cm} / \mathrm{hPa}] \approx 1.9[\mathrm{~cm} / \mathrm{hPa}]
$$

$2^{\text {nd }}$ order

$$
\left|J_{g}\right| \frac{\Delta h[\mathrm{~cm}]}{\Delta g[\mu \mathrm{gal}]}=\frac{49-(-0.3)}{5139-4860}[\mathrm{~cm} / \mu \mathrm{gal}]=\frac{52}{279}[\mathrm{~cm} / \mu \mathrm{gal}] \approx 0.2[\mathrm{~cm} / \mu \mathrm{gal}]
$$

The $J_{p}$ of the example of Figure 9(a) \& Figure 9(b) is within the standard of the events observed in the Gulf/Porto of La Spezia (Table 2). The $J_{g}$ indicates the metrological effectiveness of the gravimeter in use as a forcing phenomenon meter.

\section{The $K$ Factor and Its Computation}

The full description of the phenomenon of hydrostatic tides is obtained if, in addition to the amplitude ratio between forcing (variation of density of the atmosphere) and forced (tidal wave of compensation), the delay $K$ of arrival arrival of the forced with respect to arrival is defined of forcing. $K$ is of fundamental importance in the safety of port waterside activities as it indicates the useful time before the arrival of the hydrostatic tide wave. The value of this parameter can be obtained in two ways: geometric comparison (automatic) on the LP graphs of the tide signals and of the pressure-gravity signals or amplitude comparison in the frequency domain of these signals. The second one has the advantage of allowing a more accurate evaluation of the computations (14), (15).

$$
\begin{aligned}
& K_{p}=\Phi_{h}-\Phi_{p}=\left\lfloor\tan ^{-1}\left|\frac{b_{h}}{a_{h}}\right|\right\rfloor-\left\lfloor\tan ^{-1}\left|\frac{b_{p}}{a_{p}}\right|\right\rfloor \\
& K_{g}=\Phi_{h}-\Phi_{g}=\left\lfloor\tan ^{-1}\left|\frac{b_{h}}{a_{h}}\right|\right\rfloor-\left\lfloor\tan ^{-1}\left|\frac{b_{g}}{a_{g}}\right|\right\rfloor
\end{aligned}
$$

where $a, b$ Fourier harmonic coefficients (10), (11):

and

$T=$ period of the harmonic considered.

$K_{p}=$ delay of marine compensation to the variation in atmospheric pressure.

$K_{g}=$ delay of marine compensation to the variation in local gravity.

$\Phi_{p}=$ phase (time) signal atmospheric pressure variation.

$\Phi_{g}=$ phase (time) signal local of gravity variation.

$\Phi_{h}=$ phase (time) signal of sea depth variation.

$g=$ local gravity.

$h=$ sea level. 
With reference to Figure 6(b) and to the computations (14) and (15) the values of the delays of the hydro-barometric tidal wave $K_{p}, K_{g}$ have been computed. The delays are computed from the time of setting of the geodetic imbalance coming from the variation of atmosphere's weight. In (12) the computation is performed with respect to the $P_{a t m}$ signal, in (13) with respect to the $g_{l o c}$ signal. The experimental values are:

$$
\begin{aligned}
& K_{p}=\Phi_{h}-\Phi_{p}=1^{\mathrm{h}} 15^{\mathrm{min}}, \\
& K_{g}=\Phi_{h}-\Phi_{g}=3^{\mathrm{h}} 30^{\mathrm{min}}\left\{\begin{array}{l}
\Phi_{h}=\left|36^{\mathrm{h}} 50^{\mathrm{min}}\right|_{\text {day } 2}=\left|12^{\mathrm{h}} 50^{\mathrm{min}}\right|_{\text {day3 } 3} \\
\Phi_{p}=\left|35^{\mathrm{h}} 35^{\mathrm{min}}\right|_{\text {day } 2}=\left|11^{\mathrm{h}} 35^{\mathrm{min}}\right|_{\text {day3 }} \\
\Phi_{g}=\left|33^{\mathrm{h}} 20^{\mathrm{min}}\right|_{\text {day } 2}=\left|09^{\mathrm{h}} 20^{\text {min }}\right|_{\text {day3 } 3}
\end{array}\right.
\end{aligned}
$$

As shown in (16) the analysis based on the variation of gravity produces the information (prediction of delay beetwen inducing signal - induced signal) with a greater advance $\Delta T$ with respect to the analysis based on atmospheric pressure (17)

$$
\Delta T=K_{g}-K_{p}=3^{\mathrm{h}} 30^{m}-1^{\mathrm{h}} 15^{\mathrm{min}}=2^{\mathrm{h}} 15^{\mathrm{min}}
$$

This advance in the availability of information $\left(2^{\mathrm{h}} 15^{\mathrm{min}}\right)$ (17) can be fundamental information in the management of port navigation and dockside activities.

\section{The $K$ Factor and Its Computation}

The delay $K=K[\mathrm{~h}, \mathrm{~min}]$ of the compensation wave arrival is calculated in Fourier transform. This numerical action provides a very simple and fast method of controlling $K$. But if we apply the FFT protocol directly to our raw data series we can have an unstable response as shown by the high standard deviation $\sigma 1$ 18). In fact we note that the value of the response is strongly dependent on the frequency (or wavelength) of the cut. This evidence can significantly decrease $K$ s operational forecasting effectiveness. The $K$ values dispersion of each HP function analyzed is depending on the shear wavelength of the HP frequency filter (Figure 10, Table 3)

$$
\sigma=\sqrt{\frac{\left(x_{1}-\mu\right)^{2}+\cdots+\left(x_{13}-\mu\right)^{2}}{\mathrm{l}^{2}}} \rightarrow \sigma_{K} \cong 10 ; \sigma_{K_{C B}} \cong 4
$$

This problem is significantly reduced by the use of a numerical smoothing operator that stabilizes the FFT action. This is more valid for elaborations in short data windows ( $\sigma 2)$ (Figure 10, black line; Table 3, third column). In the present case the "cosine bell" smoothing operator is used 20). Considering the data set of length

$$
-(L+M) \rightarrow L+M
$$

where

$L=$ series to be analyzed.

$M=2 L / 10$. 
Table 3. Delay $K$ between forcing signal and forced signal. Time lag of arrival of the hydrostatic compensation wave. HP = cut wavelenghts of smoothed signals used for delay calculation. $K=$ delay computed by filtered signals, $K_{C B}=$ delay computed by filtered and smoothed data. Underscored data $(135 \mathrm{KCB}$ column $)=$ value of the cutoff frequency of the filtered signal utilizzato in this article. (NOTE: $\mathrm{HP}_{\text {wavelenght domain } \Lambda} \equiv \mathrm{LP}_{\text {frequency domain fz }}$ ).

\begin{tabular}{ccc}
\hline$\Lambda_{\mathrm{LP}}\left[\min \mathrm{E}^{3}\right]$ & $K[\min ]$ & $K_{C B}[\mathrm{~min}]$ \\
\hline 1.44 & 155 & 142 \\
1.38 & 159 & 139 \\
1.32 & 148 & 144 \\
1.26 & 162 & 143 \\
1.2 & 139 & 152 \\
1.14 & 141 & 139 \\
1.08 & 138 & 135 \\
1.02 & 145 & 142 \\
0.96 & 167 & 139 \\
0.9 & 140 & 142 \\
0.84 & 144 & 138 \\
0.78 & 151 & 146 \\
0.72 & 139 & 140 \\
\hline
\end{tabular}

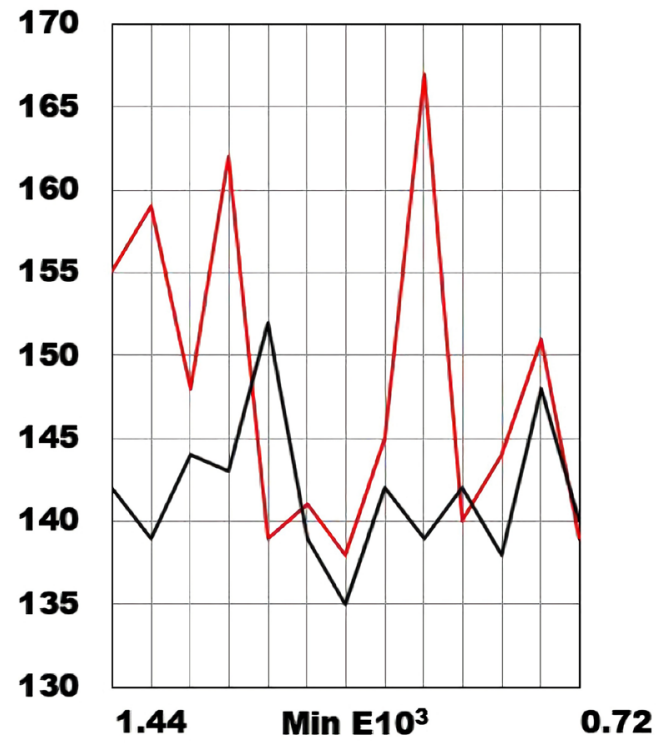

Figure 10. Dispersion of $K: X$ [min] = HP filter cut-off wavelength; $Y$ [min] = delay of the filtered signals (between the time of variation of the atmospheric pressure and the time of variation of the sea level). Red line $=$ HP filtered data, black line $=$ filtered and smoothed HP data.

Each $n^{\text {nt }}$ sample of (19) is multiplied, in the time domain, by

$$
C B_{n}=\left\{\begin{array}{lc}
\frac{1}{2}\left[1+\cos \frac{\pi(n+L)}{M}\right] & -(L+M)<n<-L \\
1 & -L \leq n \leq L \\
\frac{1}{2}\left[1+\cos \frac{\pi(n-L)}{M}\right] & L<n<L+M
\end{array}\right.
$$

the numerical operator (20) does not pollute the $L$ series subjected to analysis 
and avoids the well known FFT reconstruction problems of non-derivable edges (box car $\rightarrow$ causal function). In the case under discussion the $2 \mathrm{~L}$ series consists of 1440 samples $(24[\mathrm{~h}$,$] sr 1[\mathrm{~m}])$ so the length of the smoothimg segments is $|L+M|=144[\mathrm{~min}]$ and the length of the complete series is Fx of 1728 data (from -864 to +864 ) [13]. The numerical procedure CB is not heavy and the advantages it produces in the stability of the computation are relevant. Experience shows in the automatic calculation processes this data manipulation is, in general, a useful option. This is true especially for medium-short numerical series. Recalling that the hydro-barometric tide events can have periods of several days but they are recorded with a very low frequency $(1 / 1 \mathrm{~h}=$ sampling rate $1 \mathrm{~h})$ the $\mathrm{CB}$ action may be often very useful.

\section{The Newtonian Harbour Meteotide Stations}

\subsection{Ist Order: Barometric Station}

The measurement and forecasting of $1^{\text {st }}$ order is based on standard maregraphyc stations. In general, a mareographyce station consists of a mareograph and of its TLC system. The mareograph is often associated with some meteorological instruments completing the monitoring of the meteo-marine environment (barometer, anemometer, hygrometer, ...). This type of station is able to provide the necessary and sufficient information to apply the $1^{\text {st }}$ order measurement and forecasting procedure of tidal waves amplitude of hydrostatic origin (by means mareograph and barometer). Figure 11 shows the flow chart for the $J_{p}$ computation that is the foundamental parameter for the $1^{\text {st }}$ order hydrobarometric tides forecast.

Mareograph and barometer measure the sea level variation and of the atmospheric pressure. The informations are transferred to the system CPU by TLC (the TLC option chosen for the network of Figure 6 is the telephone card). The CPU correlates the $J_{p}$ of a congruous number of single events (at least about 10) to built the statistical value of $J_{p}$ (also called portual $J_{p}$ standard) and its dispersion $\sigma(18)$. By means of the statistical $J_{p}$ and of the forecast of the atmospheric pressure variation [14] [15] [16] it is possible to carry out forecasts of amplitude of the hydrostatic tides. This result $\left(\gamma_{p}\right)$ is obtained by multiplying the port $J_{p}$ by the forecasted $\Delta P_{a t m}$. The forecast time of the hydrostatic tide is the forecast time of the $\Delta P_{\text {atm }}$ (Figure 12). The accuracy of the forecast is indicated by $\sigma$ of the $J_{p}$ (18)

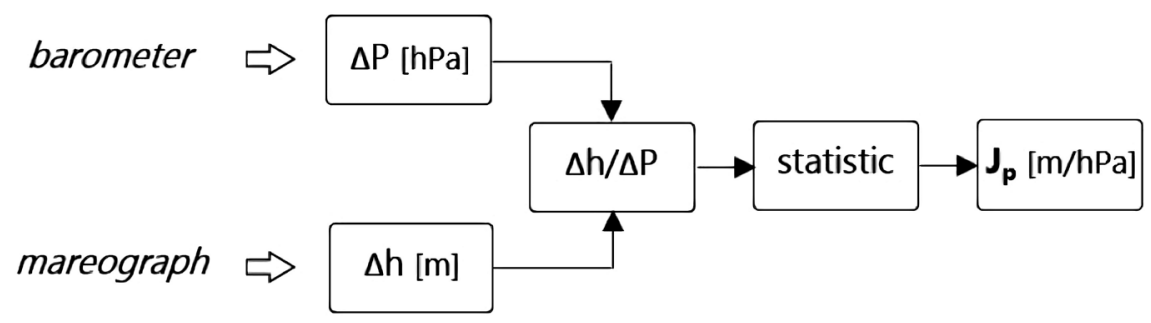

Figure 11. Flow chart for the statistical calculation of $J_{p}$. 


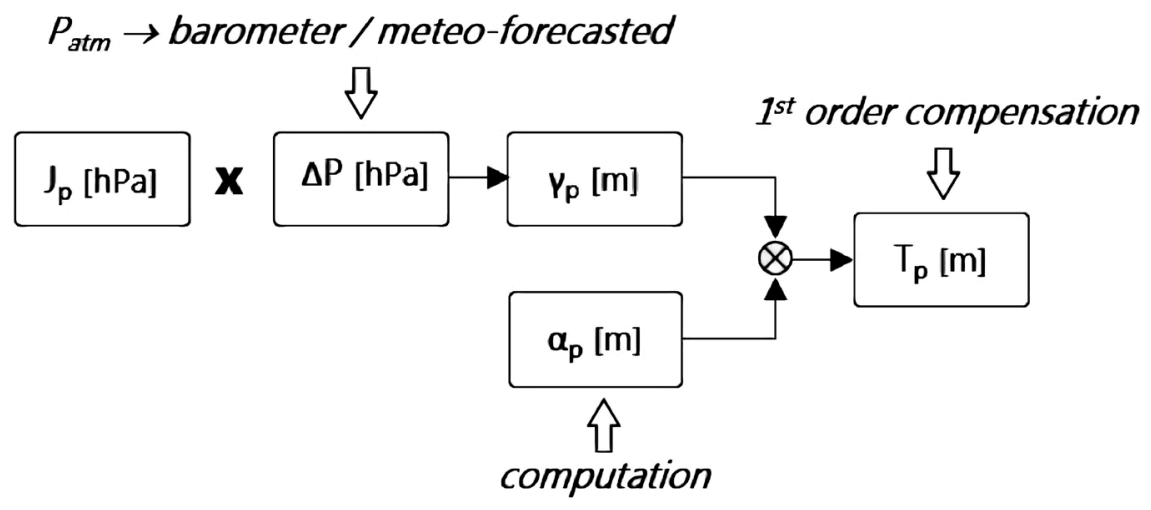

Figure 12. Flow chart of the computation of the compensated tide Tp of $1^{\text {st }}$ order. $J_{p}=$ harbor hydro-barometric inverse factor, $\Delta P=$ variation of atmospheric pressure (measured or forecast), $\alpha=$ astronomical component of the tide, $T_{p}=$ tide $(\gamma)$.

To obtain the prediction of $\Delta h$ (first order tide compensation), the forecasted $\gamma_{p}$ is algebraically added to the astronomical component $\alpha$ provided by the astronomical tide tables (Figure 12). In practice the meteorological forecast of the variation of atmospheric pressure is transformed into the forecast of hydrostatic variation of the sea level and added to the astronomical tide $\alpha$. At today the barometric forecasts included in the Italian national network system (Figure 6(a)) are, on an experimental basis, 12 [h], 24 [h], 48 [h] (Figure 13). The accuracy of these forecasts depends on two factors. The first one is the precision of the statistical determination of the multiplicative factor $J_{p}$, the second one is the accuracy of the atmospheric pressure variation forecast. More shorter the prediction time more accurate the prediction.

After 12 hours, in the current experimental asset, the Newtonian station abandons the meteorological forecasting and moves on to direct barometric forecasting extrapolation (instrumental reading of the atmospheric pressure variation trend and its extrapolation whit $T=2[\mathrm{~h}]) 21$ ).

$$
\begin{gathered}
48[\mathrm{~h}] \text { f. } \Delta \mathrm{p} \text { (forecasted } \Delta \mathrm{p} \text { data) } \rightarrow 24[\mathrm{~h}] \text { f. } \Delta \mathrm{p} \rightarrow 12[\mathrm{~h}] \text { f. } \Delta \mathrm{p} \\
\rightarrow 10 \text { [h] e. f. } \Delta \mathrm{p} \text { (extrapolated } \Delta \mathrm{p} \text { data) } \rightarrow \rightarrow 8 \text { [h] e. f. } \Delta \mathrm{p} 6[\mathrm{~h}] \text { e. f. } \Delta \mathrm{p} .
\end{gathered}
$$

\section{2. $2^{\text {nd }}$ Order: Newtonian Station}

Although some preliminary statistical correlation studies "long-term forecast of atmospheric pressure variation, local gravity variation forecast" (correlation time $>24[\mathrm{~h}]$ ) have given interesting results, at today no conclusive results have been achieved. Barometry therefore remains an integral part of the hydrostatic port tidal forecasting process for the remote forecasting sector.

Instead for the proximity forecast sector the use of the gravimeter is very important because it adds precision to the determination of this forecast sector (Figure 14). In the hours strictly preceding the arrival of the maximum atm pressure variation $(T<6[\mathrm{~h}]), J_{g}$ is more precise than $J_{p}$. This precision gain has applicative value in cases of particular maritime transits (ei transit of ships in limit draft conditions). 


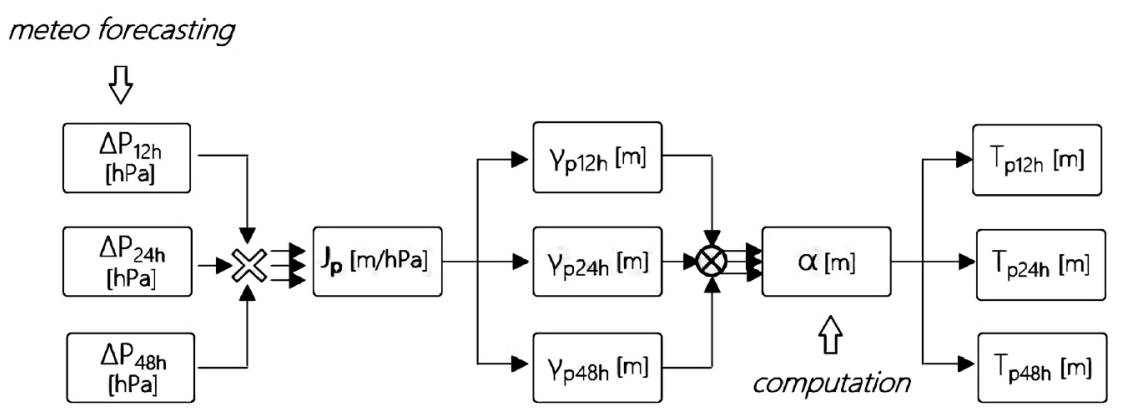

Figure 13. Flow chart for the 12, 24, 48 [h] forecast oof the tidal hydrostatic component $(\gamma)$ amplitude and of the corresponding total harbour tide $(\alpha+\gamma)$.

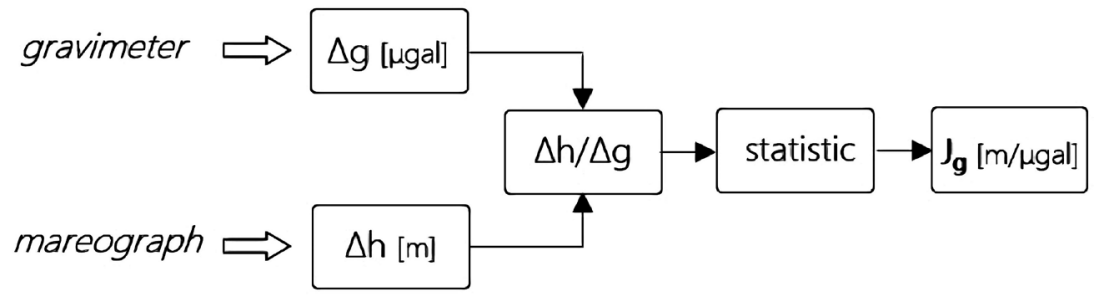

Figure 14. Flow chart for the statistical calculation of $J_{g}$.

The role of the gravimetric forecasting system (Figure 15) is fundamental in proximity forecasting also because this system provides forecast values fin advance with respect to the barometric one (Figure 9(b)). The response of the gravimeter is more agile than the barometer one because the variation in gravity is faster than pressure variation. This advance, at the outset, is estimated at around 60 - 90 [min]. This time interval can be very useful to support the decision to start docking operations or to authorize border transits. The merge of the two forecasting techniques (barometric and gravimetric) produces the best approximation possible by entrusting the remote forecast to the barometer and the proximal to the gravimeter. Therefore the Newtonian meteo-sea station consists of both the barometric component (standard maregraphyc station) and the gravimetric one (Newtonian component) (Figure 16).

In the current experimental protocols, after the prediction at $6[\mathrm{~h}]$, the algorithm migrates into the Newtonian area to use the local gravity variation data for the amplitude forecast and the gravimetric $K$ (LP 135 [min]), Figure 9(b), Table 3 ) for delay. The choice to use the data coming from the cut wavelenght $=135$ [min] is conservative. In fact the signals coming from this filter produce lower delay predictions between inducing phenomenon (variation of $P_{a t m}$ ) and induced phenomenon (sea level variation).

\section{The Italian Maregraphic Network: Same Examples}

Below we show some examples (raw data) to quantitatively visualize the real effects of the hydrostatic tide in some Italian ports (Figure 6(a)). The graphs show the values of the atmospheric pressure variation (inducing phenomenon, red line) and of the consequent sea level variation (induced phenomenon, black 


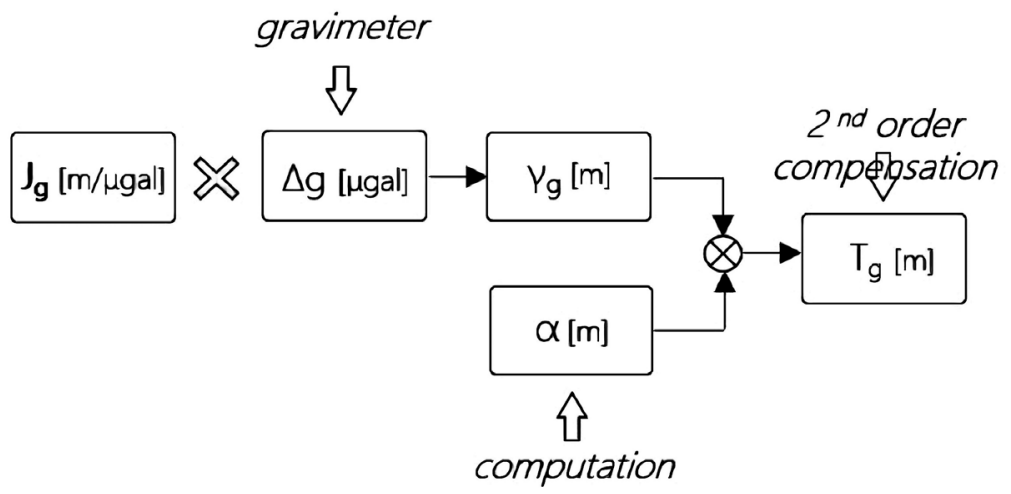

Figure 15. Flow chart of the proximity forecast computation (forecast time $\leq 6[\mathrm{~h}]$ ) of the hydrostatic tidal component $(\gamma)$ amplitude from gravimetric measures.

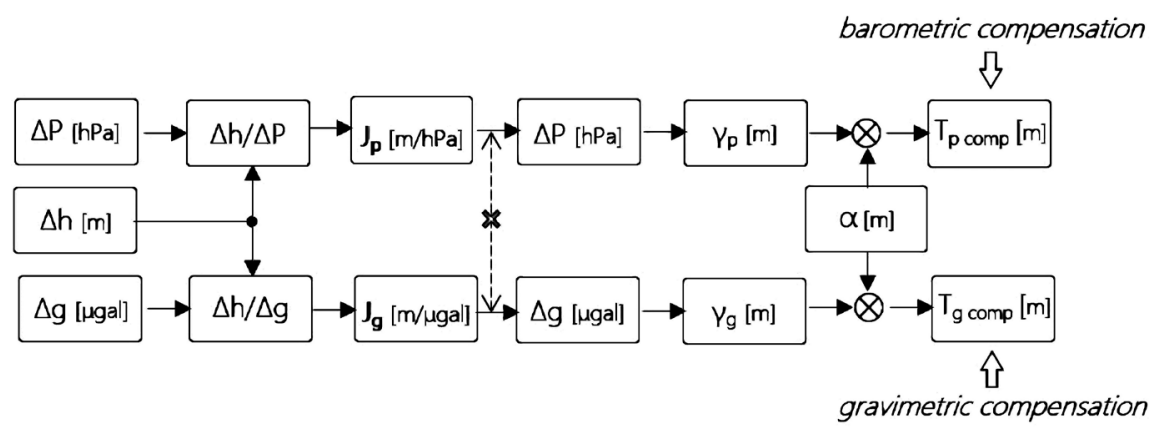

Figure 16. Flow diagram for the barometric and gravimetric forecast of the tidal hydrostatic component $\left(\gamma_{p}, \gamma_{g}\right)$ and of the total port tide $\left(T_{p}, T_{g}\right)$.

line). All the events of Figures 17-19 (a, b, c, d) took place with wind speed $v<3$ [knots]. The records come from the standard mareographyc stations (Figure 6(a)) of the ports of IMP_11 (Figure $17 \mathrm{a} \rightarrow \mathrm{d}$ ), Genova GNV_02 (Figure $18 \mathrm{a} \rightarrow$ d) and Civitavecchia CVT_06 (Figure $19 \mathrm{a} \rightarrow \mathrm{d}$ ).

LEGEND (Figures 17-19): $X=T$ [dd_mm_yy], sampling rate $s=1$ [h], $Y$ left (red line) Atmospheric Pressure [hPa], $Y$ right (black line) sea level variation [m]

- Station1: Imperia IMP_11(*)

- Station 2: Genova GNV_02 $\left(^{*}\right)$

- Station 3: Civitavecchia CVT_06 $\left(^{*}\right)$

$\left.{ }^{*}\right)$ Data collection: ISPRA Servizio Mareografico-Ministero dell'Ambiente e della Tutela del Mare e del Territorio, Italia Republic. Open source.

\section{Conclusions}

The qualitative observation of changes in sea level in Italian ports showed the presence of exceptional phenomena of high (super-high) and low (super-dry) tide both in amplitude and duration. In the last decade these phenomena have increased in frequency up to severely interfere with the maritime activities of various ports. The statistical study of the phenomenon has made it possible to associate these anomalous tidal waves with the variations in atmospheric pressure 

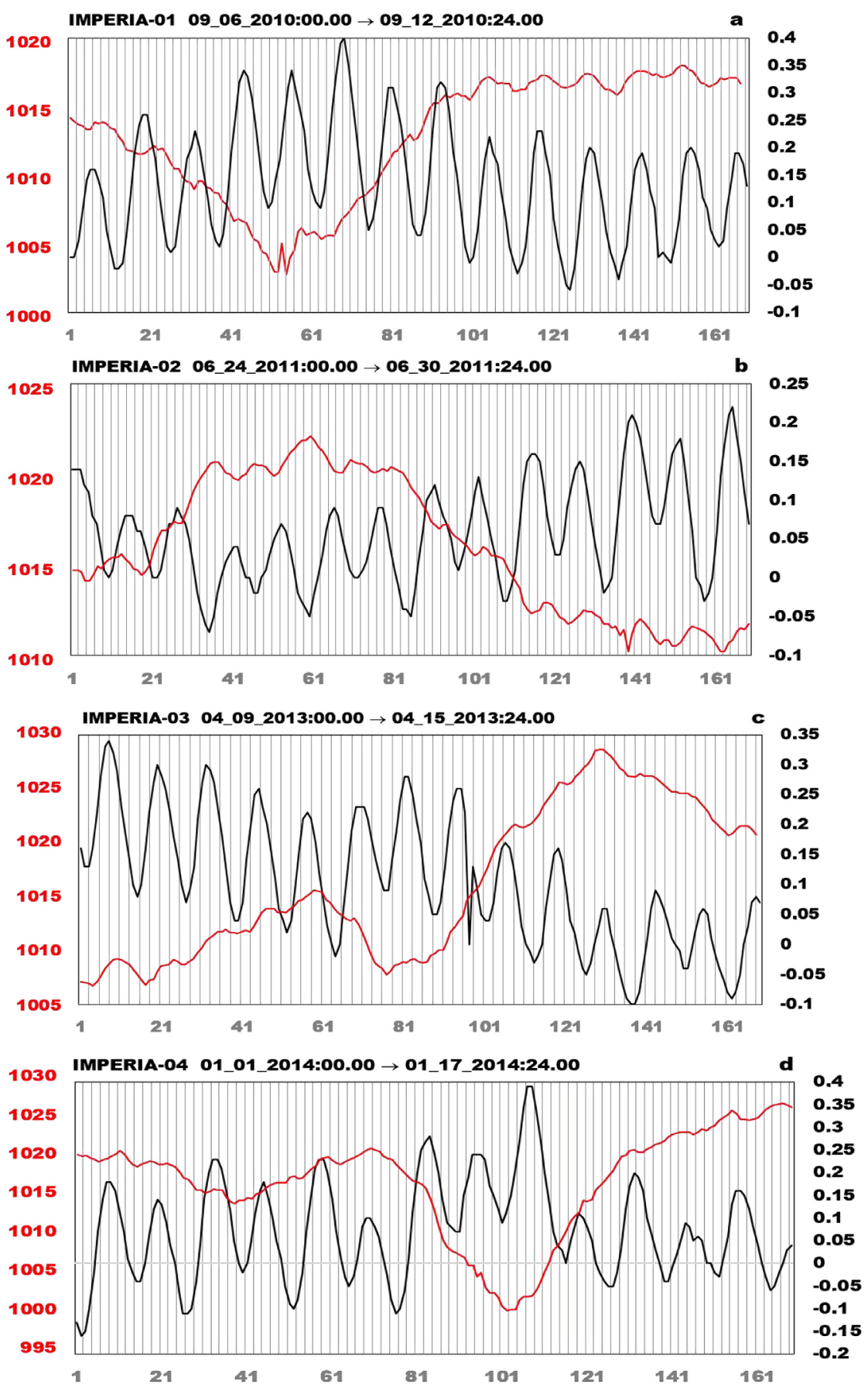

Figure 17. (a-d) Red line atmospheric pressure [hP], black line sea level [m].

and therefore to frame the phenomenon in the field of the hydrostatic relationship atmosphere-sea level (ratio of weight of the atmosphere: sea level). Technological studies (MeNFor project Meteotide Newtonia Forecasting Tecnoproject) and phenomenological studies (GraMAS project Gravimetric Maritime Automatic System for Port Navigation Safety) have made it possible to quantify the amplitude of the hydrostatic component for these tide waves. The time relationship between the arrivals of the inducing phenomenon (variation of atmos 

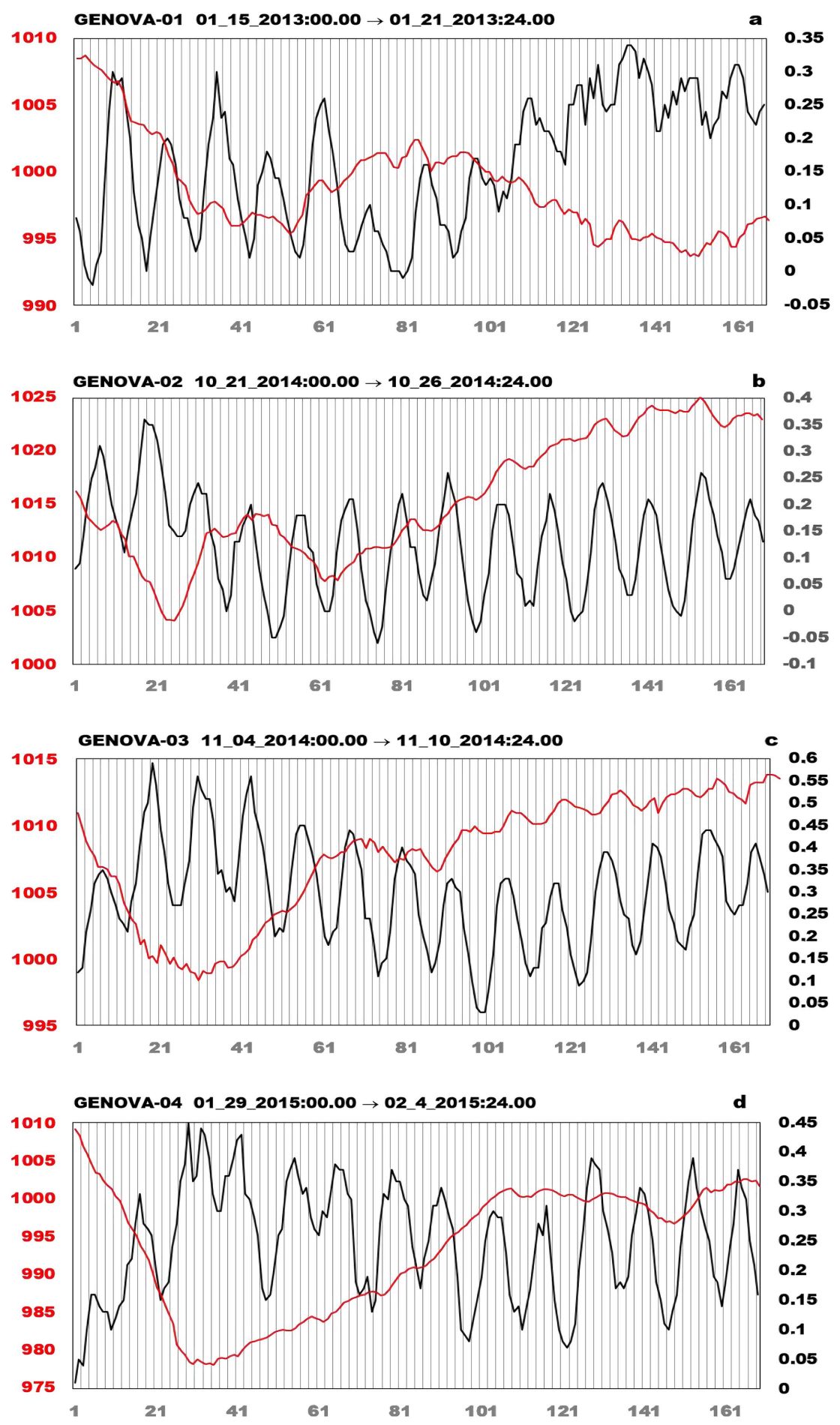

Figure 18. (a-d) Red line atmospheric pressure [hP], black line sea level [m].

pheric pressure) and the induced hydrostatic response (inverse variation of the sea level) in various Italian ports has also been defined and therefore the forecast parameters of the hydrobarometric tides in several Italian ports have been defined. In particular, the phase difference between the barometric and gravimetric signals and the hydrostatic tide one indicates the delay of the hydrostatic tidal 

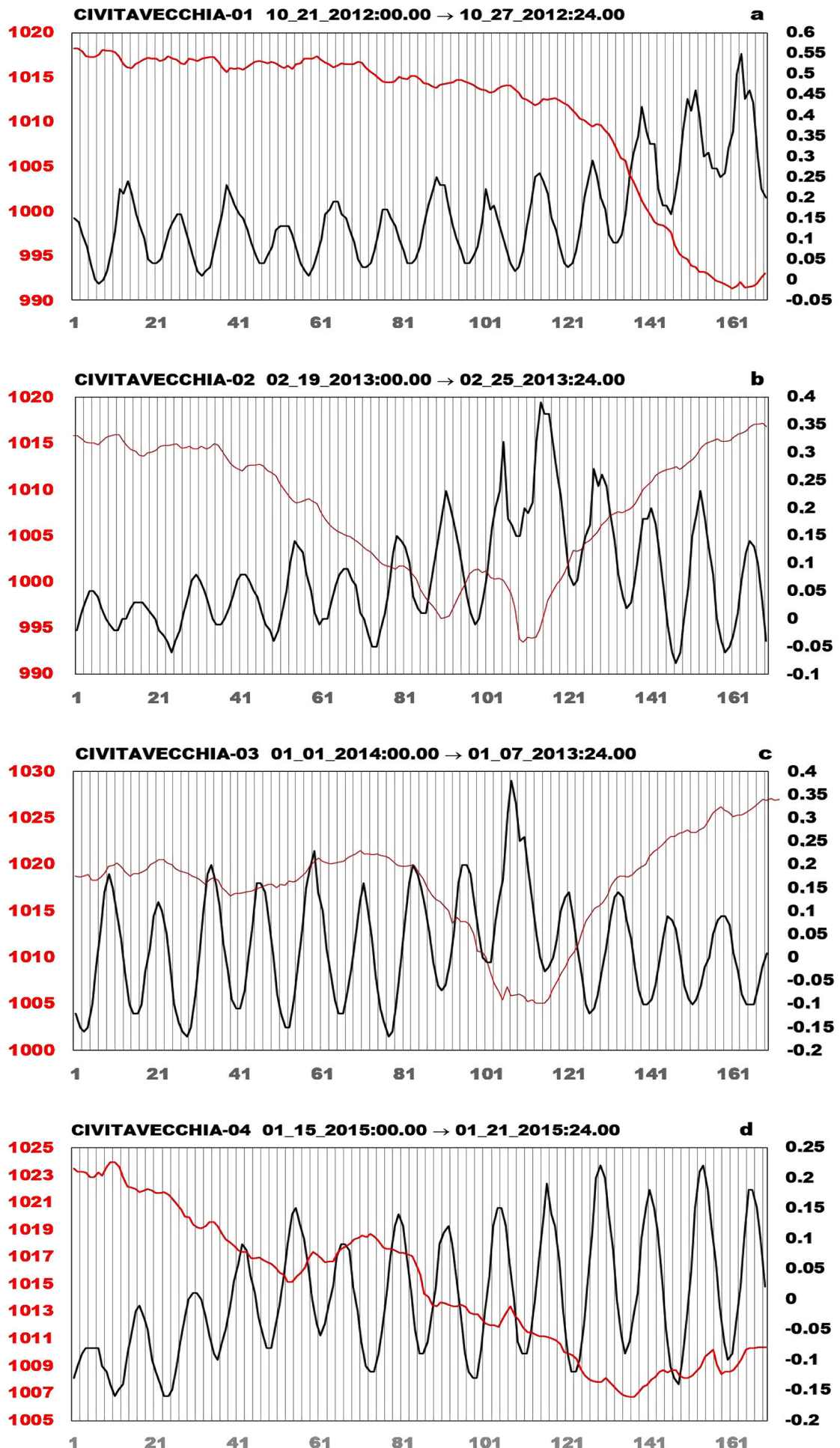

Figure 19. (a-d) Red line atmospheric pressure [hP], black line sea level [m].

wave with respect to the variation of local atmospheric pressure. This delay, like the amplitude, is characteristic of each port and it is substantially constant over time. Therefore, it can be associated with the forecasts of atmospheric pressure variation to obtain forecasts of the port sea level hydrostatic fluctuation. The 
standard meteo-mareographic stations can be used for the quantitative prediction of the amplitude and time of arrival parameters of these phenomena based on barometric measurements. The use of the gravimeter (Newtonian component) has substantially implemented the short-time forecasting accuracy. The integrated forecast (long period = barometric, short period = gravimetric) has allowed to measure and predict the phenomenon with sufficient precision to satisfy the needs of the port maritime traffic and to the ordinary and extraordinary quay operations. The introduction of this new technique for predicting the hydrostatic port tide parameters has an ordinary use: optimizing moorings and coastal navigation and their safety and improving the design of the sizing of coastal and seabed structures. The technique can be used also in case of maritime accident. In particular, for example, it is useful to forecast of the real sea level during the refloating actions in ship stranding accidents or to improve the tracking precision of the movement of non-water-soluble polluting substances (for example hydrocarbons). Hydrobarometric meteomareography has been successfully used in several Italian ports for experimental periods lasting between 6 and 12 months. Also its use in extraordinary cases has shown high operational effectiveness (e.g. checking the stability of the Costa Concordia ship during the wreck recovery operations (Isola del Giglio, January 2012) and the refloating operations of the stranded Sigma ship (Port of Livorno, January 2017)).

The tide and atmospheric pressure data presented are owned by the Serevizio Mareografico-ISPRA-Ministero dell'Ambiente e della Tutela del Mare e del Territorio-Repubblica Italiana. They are available on the website of this State organization.

\section{Acknowledgements}

This research action was coordinated by "Commissione Nazionale di Studio dei Flussi di Marea Meteorologica per la Sicurezza della Navigazione di Approccio Portuale, delle Opere Marittime e dell'Ambiente Marino Portuale (COM.SI.PORT)-CONSUPLP SEZ. III, Ministero delle Infrastrutture e Trasporti-Italian Republic" (Gra.M.A.S. Gravimetric Maritime Austomatic Aid to Port Navigation System research action 2007-2014). EU-PRAI-FESR Regione Liguria and Genova, La Spezia, Marina di Carrara, Livorno, Piombino, Civitavecchia, Cagliari, Bari, Ancona, Ravenna Port Authorities (old definition) have supported this research action. Special thanks to Italian Navy (CSSN and COMSUBIN-La Spezia ITA) and CMRE (North Atlantic Treaty Organization La Spezia ITA) for the logistic and technological support to the Newtonian mareographyc station.

Thank you very much to everybody.

\section{Conflicts of Interest}

The author declares no conflicts of interest regarding the publication of this paper. 


\section{References}

[1] LeTraonand, P.Y. and Gauzelin, P. (1997) Response of the Mediterranean Mean Sea Level to Atmospheric Pressure Forcing. Journal of Geophysical Research, 102, 973-984. https://doi.org/10.1029/96/C02777

[2] Tsimplis, M.N. (1995) The Response of Sea Level to Atmospheric Forcing in the Mediterranean. Journal of Coastal Research, 11, 1309-1321.

[3] Rosen, D.S. and Raskin, L. (2004) Wind and Wave Effects on Sea Level Measurements. Proceedings of the SEAS-RI Workshop on Sea Level Observation and Interpretation, Valletta, Malta, November 2004.

[4] Ponte, R.M. and Gaspar, P. (1999) Regional Analysis of the Inverted Barometer Effect over the Global Ocean Using TOPEX/POSEIDON Data and Model Results. Journal of Geophysical Research, 104, 5587-15601. https://doi.org/10.1029/1999JC900113

[5] Stocchino, C. and Scotto, V. (1970) Il livello medio marino e la pressione atmosferica nel porto di Genova. Bulletin de IInstitut océanographique de Monaco, 69, 1399-1418.

[6] Faggioni, O., Arena, G., Bencivenga, M., Bianco, G., Bozzano, R., Canepa, G., Lusiani, P., Nardone, G., Piangiamore, G., Soldani, M., Surace, L. and Venzano, G. (2006) The newtonian approach in the meteorological tide waves forecasting: preliminary observations in theEast Ligurian harbours. Annals of Geophysics, 49, 1177-1187

[7] Wunsch, C. and Stammer, D. (1997) Atmospheric Loading and the Oceanic "Inverted Barometer” Effect. Reviews of Geophysics, 35, 79-107. https://doi.org/10.1029/96RG03037

[8] Mosetti, F. (1969) Oscillazioni del livello medio marino a Venezia in rapporto con le oscillazioni di pressione atmosferica. Bollettino di Geofisica Teorica e Applicata, 11, 264-277.

[9] Faggioni, O., Leoncini, D. and Soldani, M. (2013) Metrological Analysis of Geo-Potential Gravity Field for Harbor Waterside Management and Water Quality Control. International Journal of Geophysics, 2013, 1-12. https://doi.org/10.1155/2013/398956

[10] Faggioni, O., Lusiani, P., Piangiamore, G. and Soldani, M. (2004) Statistical Methods in the Meteorological Tide Forecasting: The Newtonian Choice. Proceedings of First Mediterranean Workshop in Marine Geophysics, Portovenere, Italy, 26-28 October 2004.

[11] Vilibic, G., Paklar, B., Dadic, V., Ivankovi'c, D. and Cupic, S. (2007) Qualitative Analysis of Old and New Sea Level Measuring Techniques and Their Data Consistency. IEEE Journal of Oceanic Engineering, 32, 428-435.

https://doi.org/10.1109/JOE.2006.880132

[12] Faggioni, O. (2018) The Fourier Notation of the Geomagnetic Signals Informative Parameters. Signal and Information Processing, 9, 153-166.

https://doi.org/10.4236/jsip.2018.93009

[13] Faggioni, O. (2019) The Information Protection in Automatic Reconstruction of Not Continuous Geophysical Data Series. Journal of Data Analysis and Information Processing, 7, 208-227. https://doi.org/10.4236/jdaip.2019.74013

[14] Lynch, P. (2008) The Origins of Computer Weather Prediction and Climate Modeling. Journal of Computational Physics, 227, 3431-3444.

https://doi.org/10.1016/j.jcp.2007.02.034 
[15] Lynch, P. (2006) Weather Prediction by Numerical Process. In: The Emergence of Numerical Weather Prediction, Cambridge University Press, Cambridge, 1-27.

[16] Krishnamurti, T.N. (1995) Numerical Weather Prediction. Annual Review of Fluid Mechanics, 27, 195-224. https://doi.org/10.1146/annurev.fl.27.010195.001211 